\title{
Perspectives of medical students and teaching faculty on teaching medicine in their native language
}

Ziyad Alrajhi, ${ }^{1}$ Ali Alhamdan, ${ }^{1}$ Musab Alshareef, ${ }^{1}$ Osama Almubaireek, ${ }^{1}$ Mahmoud Mahmoud, ${ }^{2}$ Aamir Omair, ${ }^{2}$ Emad Masuadi ${ }^{2}$ and Bashir Hamad ${ }^{3}$

${ }^{1}$ College of Medicine, King Saud bin Abdulaziz University for Health Sciences, Riyadh, Saudi Arabia. ${ }^{2}$ Department of Medical Education, College of Medicine, King Saudi bin Abdulaziz University for Health Sciences, Riyadh, Saudi Arabia. ${ }^{3}$ Sudan Medical Specialization Board, Sudan Khartoum. International University of Africa, Khartoum, Sudan. (Correspondence to: Ziyad Alrajhi: alrajhiziyad@gmail.com).

\begin{abstract}
Background: One of the basic policy questions to be decided at the inception of medical education institutes is the language of instruction.

Aims: This study explored the perspectives of medical faculty and students at a college in Saudi Arabia on the language of instruction in medical education.

Methods: A cross-sectional survey of undergraduate medical students and full-time faculty members at a medical college in Riyadh, Saudi Arabia, was conducted in 2016. Each participant completed a self-administered, validated 28-item questionnaire.

Results: The total number of students and faculty who responded were 468 (76\%) and 37 (93\%) respectively. Most students and faculty members agreed that studying in English enables a better access to medical information ( $n=457,91 \%$ ) and more job opportunities $(n=419,83 \%)$. Less than $15 \%$ of the students preferred to be taught in Arabic in most of the curriculum aspects except for communication skills $(n=131,28 \%)$ and the Objective Structured Clinical Examination (OSCE) $(n=119,26 \%)$.

Conclusions: Most medical students and faculty members preferred English as the language of instruction for medical education and did not believe that teaching medicine in Arabic should be sought as a future goal.

Keywords: medical education, native language, English, Arabic, Saudi Arabia.

Citation: Alrajhi Z; Alhamdan A; Alshareef M; Almubaireek O; Mohamud M; Omair A; et al. Perspectives of medical students and teaching faculty on teaching medicine in their native language. East Mediterr Health J. 2019;25(8):562-566. https://doi.org/10.26719/emhj.18.073

Received: 30/08/17; accepted: 30/01/18

Copyright (C) World Health Organization (WHO) 2019. Some rights reserved. This work is available under the CC BY-NC-SA 3.0 IGO license (https:// creativecommons.org/licenses/by-nc-sa/3.o/igo).
\end{abstract}

\section{Introduction}

Nearly every year, new medical colleges are established throughout the world in response to the shortages that exist in health care personnel. One of the basic policy questions to be decided at the inception of these medical education institutes is the language of instruction. There is currently no global standard in this regard: different medical colleges around the world use different languages of instruction. About $37 \%$ of medical colleges outside the United States of America and Canada use English as the medium of instruction, while only $22 \%$ of the countries in which these medical colleges are located have English as an official language (1). About $15 \%$ of medical colleges around the world use two or three languages for instruction (1).

In the Arab world, with a population of more than 400 million people distributed across 22 countries speaking mainly Arabic, only the Syrian Arab Republic uses Arabic as the language of instruction in all its medical colleges (2). Arabic has been used in the country since 1918 when the first medical college was established (3). English, on the other hand, constitutes the primary language of instruction in most of the medical colleges in Arab countries, apart from four countries that use French: Tunisia, Morocco, Algeria, and Mauritania.
The choice of using the native language for instruction in medicine has a significant impact on the students who study it, as it facilitates the process of acquiring knowledge and utilizes the optimum potential of the students. If the language of instruction is not their native language, students begin their college journey with a challenge, encountering a curriculum in a language that is unfamiliar and different, which leaves the student with the burden of trying to keep their grades up and understand new terminology (4). The English language barrier has been shown to be associated with poor student performance (5-7), and a poor ability to communicate with patients $(8,9)$. In the British Council report "English as a medium of instruction: a growing global phenomenon", teaching medicine in English when it is not the native language may lead to difficulties when those students or graduates start their clinical practice and interact with patients who might not know any English at all (10). On the other hand, opponents of the native language choice associate instruction in English with better job opportunities, social status, and self-esteem (11,12). Furthermore, students in Egypt have overwhelmingly expressed concern over Arabization, as it would add a new burden to their academic careers (9). Linguistic policies and slow Arabization processes have also been blamed for the inadequacy of specialized 
scientific materials in Arabic (12).

Previous studies have considered the attitudes of medical faculty and students towards the language of instruction $(9,12)$. It was recommended that these studies be repeated periodically to assess the emergence of new trends and to help guide new linguistic policies (12). In response to this recommendation, the present study explored the perspectives of medical faculty and students regarding the use of Arabic as the language of instruction in medical colleges in Saudi Arabia. It also investigated their perspectives on the obstacles to adopting Arabic for teaching medicine, and on the scientific, economic, and social impact of language choice in medical education.

\section{Methods}

\section{Settings and participants}

This study was conducted at King Saud bin Abdulaziz University for Health Sciences (KSAU-HS) in Riyadh, Saudi Arabia. The institution was established in September 2004 to offer health sciences programmes and uses English as the medium of instruction and assessment. The college of medicine adopted the medical curriculum from the University of Sydney in Australia. The college of medicine at KSAU-HS has two different branches, one for females and the other for males. They both use the same curriculum but the full-time teaching faculty is different in each college. Almost all the students had Arabic as the language of instruction during high school. Before entering the college of medicine, students complete two years of English and basic sciences (taught in English) study at the College of Science and Health Professions. This study approached all 613 male and female medical undergraduate students and 55 full time teaching faculty.

\section{Instrument development and data collection methods}

The research team developed a questionnaire that consisted of questions regarding demographic characteristics, awareness of the languages used to teach medicine worldwide, perceived language superiority, and language practice preference. Face and content validity were checked by four medical educators before a pilot study was conducted on 100 students and the internal consistency was assessed using Cronbach's alpha. An exploratory factor analysis was used to assess the construct validity of the questionnaire.

Timings of the questionnaire distribution were carefully selected to maximize the response rate. Student participants were approached at break times, after lectures, and at the end of the academic day. The faculty was approached during their office hours to hand them the questionnaires, which were collected the next day. Survey instruments for the students and faculty were identical except for a question about the year-of-study (students) and the respondent's position at the college (faculty). Participation in this study was voluntary and a consent form was attached to the questionnaire. The confidentiality of the study participants was ensured and all questionnaires were kept in a safe and secure place that could only accessed by the research team.

\section{Statistical analysis}

SPSS software (IBM Corp. Released 2013. IBM SPSS Statistics for Windows, Version 22.0. Armonk, NY: IBM Corp.) was used for data entry and analysis. Categorical data were presented as frequencies and percentages. A Chi-square test was used to assess the association between knowledge about language use in medical teaching worldwide and language practice preference with the baseline characteristics of the faculty and students. The test was considered to show a significant difference if the $P$-value was less than 0.05 .

\section{Results}

The questionnaire was completed by $468(76 \%)$ out of 613 students and 37 (93\%) out of 40 available faculty members. The overall Cronbach's alpha was 0.81 for the 21 Likert-type scale items; further analysis showed high reliability of the domains as well (participants' awareness about language use in medical teaching worldwide [0.89], perceived language superiority [0.71], and language practice preference [0.74]). To test the construct validity of the instrument, an exploratory factor analysis (EFA) was used that confirmed the five factors the instrument contained thereby explaining $66 \%$ of the total variance. The extraction method used was principal component analysis and varimax rotation with Kaiser normalization. Only two items, the Objective Structured Clinical Examination (OSCE) and communication skills, were misclassified by loading higher on "preference for teaching medicine in Arabic in the future" rather than "language use". The Bartlett's tests of sphericity was used to ascertain whether factor analysis can be carried out $(P$-value $<0.001)$ with a Kaiser-Meyer-Olkin measure of sampling adequacy of 0.76 .

The majority of the respondents were males for both students $(n=279,60 \%)$ and faculty $(n=26,70 \%)$, which is similar to the general distribution of the study population. The mean age of the student respondents was $22.0 \pm$ 1.8 years, while the mean age of the faculty member respondents was $40 \pm 10.9$ years. The distribution of the proportion of students who responded had a greater proportion from first and second year, this is similar to the general distribution of the study population. Of the faculty respondents, half $(n=19,51 \%)$ were assistant professors and above, while the remaining ( $n=18,49 \%)$ were lecturers or teaching assistants.

Table 1 shows the respondents' opinions about the advantages of studying medicine in English. The overall response showed high agreement for the statements that medical graduates from programmes instructed in English have better access to medical information $(n=457$, $91 \%)$ and more job opportunities $(n=419,83 \%)$. Around half of the participants agreed that medical graduates who studied in English are more competent $(n=260,51 \%)$ 


\begin{tabular}{|c|c|c|c|}
\hline & $\begin{array}{c}\text { Students } \\
\begin{array}{c}\text { [n=468] } \\
n(\%)\end{array}\end{array}$ & $\begin{array}{c}\begin{array}{c}\text { Faculty } \\
\text { [n=37] }\end{array} \\
n(\%)\end{array}$ & P-value \\
\hline Have better access to medical information & $423(91)$ & $34(92)$ & $0.79 a$ \\
\hline Are more competent & $241(52)$ & $19(53)$ & 0.99 \\
\hline Have more job opportunities & $389(84)$ & $30(81)$ & $0.75 \mathrm{a}$ \\
\hline Have a higher social status & $219(47)$ & $20(56)$ & 0.39 \\
\hline
\end{tabular}

aFishers Exact test was used for small-expected amount

and have a higher social status ( $n=239,47 \%)$. There was no significant difference between the students and the faculty for any of the four statements.

\section{Preferred language for teaching and testing}

Table 2 shows that the general selection of the preferred language was languages other than Arabic. The highest preference for the Arabic language was for communication skills by the students $(n=129,28 \%)$ and faculty $(n=2,5 \%)$. There were significant differences between students and faculty for three items: communication skills $(P=0.003)$, community doctor theme / personal and professional development sessions $(P=0.04)$, and OSCE $(P=0.002)$, which were all higher for students.

\section{Should Arabic be used as a language of instruction for medicine in the future?}

Only 159 (36\%) students and 11 (31\%) faculty members thought that teaching medicine in Arabic should be a goal that must be sought in the future, with no significant difference between the students and the faculty.

\section{The language used by lecturers in teaching}

The majority of students $(n=408,88 \%)$ and faculty $(n=35$, 95\%) stated that English is currently the language used by lecturers in teaching.

\section{Knowledge about language of instruction for medicine} worldwide

Seven randomly selected countries were provided in the questionnaire asking the participants about the language of medical instruction for these countries. Most of the respondents ( $n=394,78 \%$ ) did not know the language of instruction for medicine in various countries presented in the questionnaire.

\section{Favouring English as the language of instruction}

Participants who favoured English as the language of medical instruction gave a variety of reasons for their preference. The most notable reason was access to the best and most updated medical resources. Furthermore, they mentioned the English language as being the main language of medicine and that it must be used to be able to communicate with the medical scientific community. Moreover, many students mentioned that using English provides more job opportunities and makes it easier to pursue further training. Other notable reasons for favouring English were the availability of teaching faculty, availability of medical terminology, less learning effort, higher social status, and more competence upon graduation.

\section{Favouring Arabic as the language of instruction}

The most frequently cited reason among those who favoured Arabic as the language of instruction in medicine was that Arabic is the spoken language of their population, so using Arabic as the language of instruction would improve the quality of care by better understanding patients' complaints, helping to explain the condition to the patients, and spreading awareness to the community. Another reason cited was that Arabic, being the native lan-

\begin{tabular}{lccc}
\hline Table 2 Students' and faculty's Arabic language preference in teaching and assessment & & Faculty & P-value \\
& Students & [n=468] & $\mathbf{n}$ (\%) \\
& $\mathbf{n}(\%)$ & $0(0)$ & 0.245 \\
Lectures & $27(6)$ & $1(3)$ & 0.345 \\
Problem-based learning tutorials & $37(8)$ & $1(3)$ & 0.069 \\
Procedural skills & $62(13)$ & $2(5)$ & 0.003 \\
Communication skills & $129(28)$ & $1(3)$ & 0.712 \\
Laboratory sessions & $27(6)$ & $0(0)$ & $0.388^{\mathrm{a}}$ \\
Written examination & $21(4)$ & $1(3)$ & 0.044 \\
Community and doctor theme / personal and professional & $71(15)$ & $1(3)$ & 0.002 \\
development & & $118(25)$ & \\
Objective structured clinical examination & & & \\
\hline
\end{tabular}


guage of the students, would enable better understanding of the content and spare the time and effort required for translation. Other reasons mentioned were the need to strengthen the sense of identity and independence and the need to support the Arabic language.

\section{Discussion}

The purpose of this study was to explore the perspectives of medical students and faculty at KSAU-HS in Riyadh, Saudi Arabia on the possibility of using the Arabic language as the medium of instruction in undergraduate medical education. Approximately one-third of the students and the faculty thought that teaching medicine in Arabic was a goal that must be sought in the future; this suggests that majority of those who participated favoured English as the language of instruction. The overwhelming preference for English in this study is consistent with the published literature. A study conducted in Egypt showed that only $9 \%$ of the students thought that teaching medicine in a foreign language was a major obstacle (9). Approximately $70 \%$ of the students surveyed by Sabbour et al. in Egypt indicated a preference for using Arabic to learn communication skills (9). This contrasts with the findings of the present study, where only $28 \%$ of the participants reported such a preference.

Another study conducted in Saudi Arabia found similar results and showed that $96 \%$ of the study participants considered English to be superior to Arabic, and that $82 \%$ of them thought that English was more appropriate for medical instruction and other scientific specialties (11). This can be explained by the fact that, for students and faculty members alike, the usage of Arabic as a language of instruction brings a sizable academic burden and fear of having to adapt to an unfamiliar educational system. Moreover, Al Jarf (2008) study also showed that most participants thought that English was the language of instruction for medical education programmes worldwide (11). However, this study found that $78 \%$ of the participants indicated that they did not know which language of instruction was used to teach medicine in other parts of the world. A study that was conducted in Libya showed that $63 \%$ of the medical students preferred to be taught in a mixture of Arabic and English (10). Ahmed et al. (2015) study showed far more acceptance of using Arabic as the language of instruction in their medical and dental education programmes compared to only $28 \%$ of participants in the present study, who indicated that Arabic could be used to teach communication skills (10).

Both the medical students and faculty members who participated in the present study preferred English as the language of instruction for medical education. Furthermore, the majority believed that using Arabic as the language of instruction should not be sought as a future goal. One of the main strengths of the present study is that the tool used was validated, and showed high internal consistency and reliability. Moreover, it included all students and full-time faculty members of both genders at a recently established medical college in Riyadh, Saudi Arabia.

A limitation of the present study is that the students and teaching faculty who were surveyed were all from one institution. Future studies should include a larger sample from different institutions. Further research is needed to better understand the applicability and the practicality of teaching medicine in Arabic. We recommend conducting a similar study at a university where the medium of instruction is a native language other than English.

Funding: This work was supported by the King Abdullah International Medical Research Center, Riyadh, Saudi Arabia.

Competing interests: None declared.

\section{Points de vue des étudiants en médecine et du corps professoral concernant l'enseignement de la médecine dans leur langue maternelle}

\section{Résumé}

Contexte : L'une des questions de politique essentielles qui se pose au moment de la création d'instituts d'enseignement de la médecine concerne la langue dans laquelle la formation sera dispensée.

Objectifs : La présente étude analyse les points de vue du corps professoral et des étudiants d'une faculté d'Arabie saoudite concernant la langue utilisée dans l'enseignement de la médecine.

Méthodes : Une étude transversale a été réalisée en 2016 auprès d'étudiants en médecine de premier cycle et de membres du corps professoral à temps plein d'une faculté de médecine de Riyad (Arabie saoudite). Chaque participant a rempli un questionnaire auto-administré et validé comportant 28 items.

Résultats : Le nombre total d'étudiants et d'enseignants ayant répondu au questionnaire était respectivement de 468 (76\%) et de 37 (93\%). La majorité des étudiants et des membres du corps professoral reconnaissait que l'enseignement dispensé en anglais permet un meilleur accès à l'information médicale $(n=457,91 \%)$ et offre davantage de possibilités d'emploi $(n=419,83 \%)$. Moins de $15 \%$ des étudiants préféraient l'enseignement dispensé en arabe dans la plupart des matières du programme, à l'exception des compétences en communication ( $n=131,28 \%$ ) et de l'Examen Clinique Objectif Structuré (ECOS) $(n=119,26 \%)$.

Conclusions : La majorité des étudiants en médecine et des membres du corps professoral privilégiaient l'anglais comme langue d'enseignement de la médecine et estimaient que l'enseignement en arabe ne devait pas constituer un objectif pour l'avenir. 


$$
\begin{aligned}
& \text { وجهات نظر طلاب الطب و أعضاء هيئة التدريس بشأن تدريس الطب بلغتهم الأم }
\end{aligned}
$$

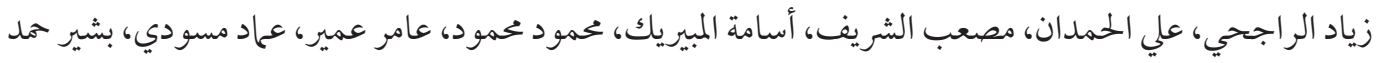

$$
\text { الخلفية: من المسائل الأساسية المتعلقة بالسياسات التي يجب اتخاذ قرار بشأنها عند إنشاء مؤسسات للتعليم الطبي هي لغة التدريس. }
$$

الأهداف: بحثت هذه الدراسة وجهات نظر أعضاء هيئة التدريس وطلاب الطب في إحدى كليات الطب بالمملكة العربية السعودية بشأن لغة التدريس في التعليم الطبي.

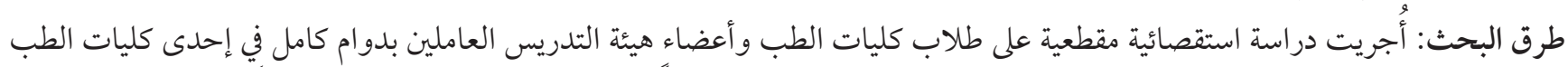

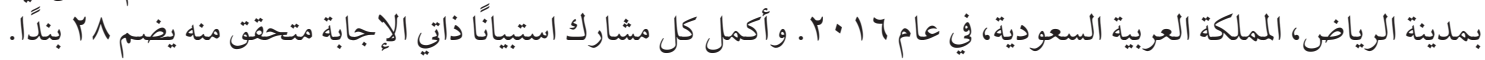

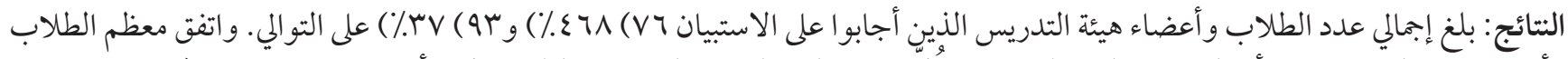

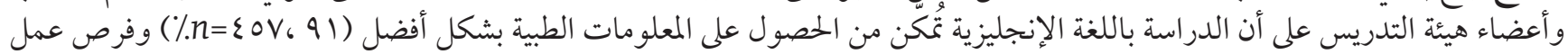

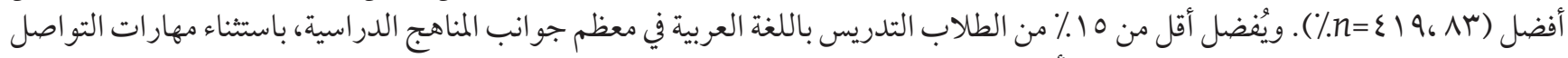

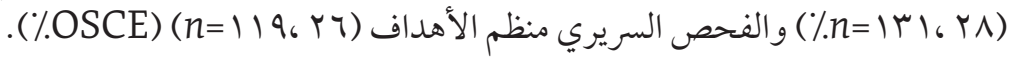

الاستنتاجات: يُفضل معظم الطلاب و أعضاء هيئة التدريس اللغة الإنجليزية في التعليم الطبي، ويعتقدون أنه لا يجب وضع تدريس الطب باللغة العربية كهدف مستقبلي.

\section{References}

1. Boulet J, Bede C, Mckinley D, Norcini J. An overview of the world's medical schools. Med Teach. 2007;29(1):20-6. http://dx.doi. org/10.1080/01421590601131823

2. Cote R. Choosing one dialect for the Arabic speaking world: a status planning dilemma. 75 Arizona working papers in SLA \& Teaching. 2009;16:75-22.

3. Al khatib B. Review of the history of the teaching of medicine in Arabic. East Mediterr Health J. 1995;1(2):284-9.

4. Anand A, Bammidi S. Medical education and training: implications for India. Ann Neurosci. 2013;20(4):133. http://dx.doi. org/10.5214/ans.0972.7531.200402

5. McLean M, Murdoch-Eaton D, Shaban S. Poor English language proficiency hinders generic skills development: a qualitative study of the perspectives of first-year medical students. J Furth High Educ. 2013;37(4):462-481. http://dx.doi.org/10.1080/030987 7X.2011.645461

6. Mandal A, Ghosh A, Sengupta G, Bera T, Das N, Mukherjee S, et al. Factors affecting the performance of undergraduate medical students: a perspective. Indian J Community Med. 2012;37(2):126-129. http://dx.doi.org/10.4103/0970-0218.96104

7. Kaliyadan F, Thalamkandathil N, Parupalli SR, Amin TT, Balaha MH, Al Bu Ali WH. English language proficiency and academic performance: a study of a medical preparatory year program in Saudi Arabia. Avicenna J Med. 2015;5(4):140-4. http://dx.doi. org/10.4103/2231-0770.165126

8. Mirza DM, Hashim MJ. Communication skills training in English alone can leave Arab medical students unconfident with patient communication in their native language. Educ Health (Abingdon). 2010 Aug;23(2):450 PMID: 20853245

9. Sabbour SM, Dewedar SA, Kandil SK. Language barriers in medical education and attitudes towards Arabization of medicine: student and staff perspectives. East Mediterr Health J. 2010;16(12):1263-1271. http://dx.doi.org/10.26719/2010.16.12.1263

10. Dearden J. English as a medium of instruction: a growing global phenomenon. Oxford: British Council / OUP; 2014. (https:// www.britishcouncil.org/sites/default/files/e484_emi_-_cover_option_3_final_web.pdf).

11. Ahmed KM, Peeran SW, Qasem Ahmed MA. Attitudes of Libyan dental and medical students toward the use of English language as a medium of instruction. Dent Med Res. 2015;3(2):53-5. http://dx.doi.org/10.4103/2348-1471.159188

12. Al Jarf R. The impact of English as an international language (EIL) upon Arabic in Saudi Arabia. Asian EFL J. 2008;10(4):193-210. 